\title{
Tourists' willingness to pay for marine resource conservation at Pulau Perhentian Marine Park, Malaysia
}

\begin{abstract}
Though Marine Parks in Malaysia are important to protect important marine resources, however, it is degraded due to human activities. In order to properly manage marine parks, economic valuation is necessary to understand the importance of marine resources conservation activities. In this study, tourist's willingness to pay (WTP) to protect marine resources at Pulau Perhentian Marine Park (PPMP) was carried out with contingent valuation method. Both single-bounded and double-bounded dichotomous choice contingent valuation methods were used to estimate tourists WTP. A total of 250 tourists were interviewed. The results showed that median WTP ranged between RM17.98 to RM21.72 and based on the number of tourist's arrivals in 2011, the aggregate benefit at PPMP would be ranged from 1.62 to 1.96 million, respectively. The results of the study could be beneficial to the Marine Park authority in setting appropriate entrance fee at PPMP and taking the adequate conservation activities to protect marine environment and resources to deteriorate further.
\end{abstract}

Keyword: Marine parks; Contingent valuation method; Willingness to pay; Dichotomous choice; Conservation 